\title{
Transnational Journalism History: Expanding Boundaries
}

Journalism history so far has mostly been a national endeavour. As a field of study, it emerged in parallel with the rise of the nation state and the construction of national identities. These first histories were mostly antiquarian, describing the history of titles and lives of famous news people. Moreover, these histories were geared towards the promotion of press freedom and aimed to shape public opinion in that respect. Most scholarship departs from the normative assumption that journalism is defined in terms of its democratic function. ${ }^{1}$ Ever since, the nation seems to be the most natural level of analysis for press and media historians. They usually study the media as national institutions inherent to national politics, laws and markets, and topically and socially geared towards national, regional or local communities with their own national language. Differences and, to a lesser extent, similarities in professional practices and news coverage are usually discussed as autonomous developments and ascribed to national peculiarities.

More recently, there has been a shift in journalism history towards more comparative, international and transnational research. In the first two approaches, scholarship to a large extent still takes place within national silos. Where in comparative research two or more national cases are contrasted, international studies are mostly focused on relating developments in multiple countries to one another and showing how (people from) these different journalistic 'cultures' interact. In contrast, transnational journalism history acknowledges that cultural forms are produced and exchanged across borders. It focuses on the interactions between agents, ideas, innovations, norms and social and cultural practices that extend beyond national boundaries. Moreover, it acknowledges the diversity and pluriformity of journalism within the national context, moving away from the idea that national journalistic cultures are coherent, discrete units of analysis. Transnational journalism history studies how interactions between these different levels impact the incorporation and adaptation of new ideas, concepts, and practices into local, national and transnational frameworks. By moving back and forth between these levels, the connective and dialectic nature of these movements is emphasised. Transnational journalism history thus treats the nation as only one level or context among a range of others, instead of being the primary frame for analysis. 
This special issue aims to expand the boundaries of scholarship and study journalism history through a transnational lens. It emerged from the third 'Transnational Journalism History Conference', organised in 2019 by the special issue editors in Groningen together with Debbie van Tuyll (Augusta University) and Mark O’Brien (Dublin City University), as part of an active network of scholars working on the topic. While previous conferences emphasised the relations between Irish and American journalism, this conference and issue had a broader scope. ${ }^{2}$ Scholars from a broad range of countries and focusing on a variety of topics came together to discuss the values of a transnational approach in their research. The articles in this special issue reflect this endeavour.

It starts with a conceptually-driven article by Yi Guo, who discusses the growing call for a transnational approach to journalism history by situating it within a broader development towards transnational approaches to history as well as within media studies at large. He discusses different conceptualisations of transnational history and outlines its merit for journalism history. Guo cements his theoretical argument by illustrating what a transnational approach can reveal about the 'interconnectedness between Chinese journalism and its overseas “others”.' By zooming in on transnational agents and networks, the article convincingly shows how transnational agents, like foreign correspondents in China, were part of informal networks of fellow journalists, who together constructed a shared identity and transnational experience that weds different cultural influences, creating a transnational community of practice, which often overlooked.

Further illustrating the value of a transnational approach to the historical development of journalism in China is the second article on US and British radio propaganda in the People's Republic of China between 1949 and 1976 by Donald Santacatarina. In his contribution he offers an insightful analysis of the considerations that went into the language policies of the British and US foreign radio broadcasts targeting a Chinese-speaking overseas community. Santacatarina shows how choices with regard to vocabulary and accents were made with an image in mind of China as a coherent nation with a shared identity. By ignoring the 'complexity of identities and space' and the pluriform nature of Chinese-speaking language communities, they reinforced the narrative of a unified nation with one standardised language that the People's Republic of China conveyed.

The third article in this special issue focuses on the transnational connections between the US and Soviet journalists in the 1960s. Erin Coyle and Elisabeth Fondren zoom in on the two trips of several members of the American Society of Newspaper Editors to the Soviet Union in 1962 and 1969 aimed at improving the availability of information for US journalists to analyse how the American 
news editors perceived their soviet counterparts, and more specifically, how they viewed press freedom in the USSR. They show how American journalists endeavoured to bridge the cultural divides between them and their Soviet colleagues. Their contributions concludes that although the cultural differences in the way journalism was understood and envisioned were too great to reconcile, the 'genuine desire to learn about life "on the other side"' was present on both sides, and did contribute to a better understanding of the differences between both countries and political systems when it comes to journalism.

The fourth contribution focuses on the US, but challenges the common assumption that 'progress comes from the north' (Hollywood and US broadcast networks). Richard Mwakasege-Minaya analyses how the emergence and further development of a Spanish-language media as part of the broader US News Media Industry was impacted and shaped by the consequences of the Cuban Revolution. He shows how there were many media professionals under the large numbers of Cuban exiles coming to the US during and after the revolution, who 'wove themselves into the fabric of South Florida's news media' leading to the expansion of the Spanish-language broadcast programmes as well as investments from Univision and Telemundo. Exacerbated by the interest in and attention for Cuba by US journalism and the media activism by Cuban exiles, the contribution shows how the Cuban Revolution and its consequences helped to 'lay the foundation for Miami to become a center of media production and distribution for the Spanish-language geolinguistic region.'

Will Mari explores how the exchange between journalists from the US and the UK shaped the early development of online journalism in both countries in the 1990s. His article shows the similarities and differences between the development of journalism around the advent of the Internet, and argues for a stronger effort to debunk the myth that newspapers squandered their online futures early on by their poor choices and lack of online strategy. His analysis shows the simplistic and teleological nature of such interpretations, which fail to acknowledge the complexities and uncertainties of trying to anticipate an unclear future. Mari concludes that 'many news organizations were not caught off guard, overwhelmed or necessarily too slow to adopt the internet,' but that they should rather be seen as 'information-society pioneers' that were very much 'aware of the big changes about to wash over the world due to the internet.'

The last three articles all zoom in on the journalistic life and work of a specific reporter, illustrating how transnational journalists were influential nodes in a larger network of journalists, acting as intermediaries between different journalistic cultures and practices. In her article, 
Stephanie Seul zooms in on Irish-Serbian female war reporter, Annie Christitch, who covered the First World War for the Daily Express in London. Her 'intimate eyewitness accounts' which were fuelled by her work as a nurse and relief worker during the First World War in Serbia were widely read and reprinted in different countries, and drew transnational attention to the suffering in warstricken Serbia. Moreover, the contribution shows how Christitch's focus on human suffering links up to the growing popularity in that period for news stories that 'were written from a specifically feminine angle' to draw in a female audience. However, as Seul points out, her stories weren't viewed as 'purely "women's stuff”' and were published in the general pages with the political and military news, illustrating the general trend of popular newspapers to increasingly choose a human interest angle to hard news.

The following article switches our attention to the transnational qualities of photography, which can easily transcend language barriers because of its visual nature. In her detailed comparative analysis of the circulation of the Randall Chase Gould's photographic coverage of the Second Sino-Japanese War (1937-1945) in different transnational communities, Anna Herren shows how through 'the dynamic inter-relation between linguistic and visual structures' the same pictures Gould made of the so-called Battle of Shanghai could take on 'alternative readings' depending on the publication and corresponding target audience they were intended for. Herren argues that photographs were not only illustrating the news, but were an important way for publishers to target different transnational audiences, reframing the same pictures to better cater to their interests and frame of reference.

In the last article of this special issue, Ana Teresa Peixinho zooms in on Portuguese novelist and journalist Eça de Queirós (1845-1900), whose transnational experiences of having lived in different cultural contexts (Havana, Newcastle, Bristol and Paris) shaped his perspective on journalism and the press, which can be considered exemplary for the way the relation between journalism and literature was conceived in Portugal at the end of the 19th century. Eça de Queirós had an ambivalent attitude towards journalism as he was highly critical of the quality and value of new forms of journalism, which were gaining ground within the newspapers at the end of the 19th century, but at the same time he worked as a journalist to sustain himself financially. In her analysis of the writings of Eça de Queirós, Peixinho shows how this ambivalence reflects a more widely shared take on the developments in journalism that move between enthusiastic anticipation and critical reluctance. 
We hope that the articles in this special issue show the value of a transnational approach to journalism history. They emphasise the importance of international networks for the transfer of norms, practices and forms, but also how individual journalists acted as change agents. Beyond personal contacts between journalists from different countries, the special issue also shows how textual conventions, ranging from genres to style, presentation and illustrations, that were 'invented' in one country inspired journalists in other countries to pick up on this and to adapt foreign examples in a local context. It demonstrates how journalism has always been a transnational institution.

\section{Notes}

1 M. Broersma, "Transnational Journalism History. Balancing Global Universals and National Peculiarities,” Medien \& Zeit, 25, no. 4 (2010): 10-15.

2 See D.R. van Tuyll, M. O’Brien, and M. Broersma, eds., Politics, Culture, and the Irish American Press, 1784-1963 (Syracuse: Syracuse University Press, 2020).

\section{Biographies}

Frank Harbers is as an assistant-professor at the Centre for Media and Journalism Studies at the University of Groningen. He received his $\mathrm{PhD}$ in 2014, which focused on the development of journalism in Great Britain, the Netherlands and France since the second half of the 19th century. In 2016 he was researcher-in-residence at the National Library of the Netherlands for which he conducted a digital humanities project into automatically classifying the genre of historical newspaper articles. In 2018, together with Huub Wijfjes, he published an edited volume on the history of the press in the Netherlands. His research interests focus on (comparative) journalism history, digital humanities approaches to journalism history, narrative forms of journalism, and journalistic innovation. Harbers has published several articles about all of these themes in refereed journals and edited volumes.

Marcel Broersma is a full professor and director of the Centre for Media and Journalism Studies at the University of Groningen. He is also the academic director of the Dutch Research School for Media Studies (RMeS) and coordinator of the national VSNU Digital Society research program. His research 
focuses on the current and historical transformation of journalism, changing media use and digital literacy, and digital humanities. Broersma published numerous articles in peer-reviewed journals, chapters, monographs, edited volumes and special journal issues on media history, social media, transformations in journalism and political communication, among which Redefining Journalism in the Era of the Mass Press, 1880-1920 (2017; edited with John Steel).

TMG Journal for Media History

Volume 24 No $(1 / 2) / 2021$

DOI

https://dx.doi.org/10.18146/tmg.808

PUBLISHER

Netherlands Institute for Sound and Vision

COPYRIGHT

Each article is copyrighted (c) by its author(s) and is published under license from the author(s). When a paper is accepted for publication, authors will be requested to agree with the Creative Commons Attribution 4.0 International License. 